\title{
Efficacy of Intracolonic Administration of Low-Molecular-Weight Heparin CB-01-05, Compared to Other Low-Molecular-Weight Heparins and Unfractionated Heparin, in Experimentally Induced Colitis in Rat
}

\author{
Giuseppe Celasco $\cdot$ Luigi Moro $\cdot$ Roberta Bozzella $\cdot$ Katia Mangano \\ Cinzia Quattrocchi · Caterina Aiello - Marco Donia · Paolo Fagone • \\ Roberto Di Marco
}

Received: 13 February 2008/Accepted: 10 April 2008/Published online: 9 May 2008

(C) The Author(s) 2008

\begin{abstract}
Purpose Parenteral administration of lowmolecular-weight heparins (LMWHs) and unfractionated heparin (UFH) resulted effective in improving the symptoms of experimental colitis in rat. Today, there is little information about their activity by intracolonic instillation. The scope of this study was to evaluate the ability of CB01-05 (a LMWH with a mean molecular weight of about 5,700), compared to a series of other LMWHs and to UFH, directly instilled into the distal colon of the rat, to ameliorate dinitrobenzene (DNB)-induced experimental colitis. Method Adult male Wistar rats underwent colitis induction by intracolonic instillation of DNB. Starting $24 \mathrm{~h}$ after colitis induction, CB-01-05 (0.005-0.9 mg), other LMWHs $(0.3-0.6 \mathrm{mg})$, and UFH $(0.6 \mathrm{mg})$ were instilled, by rectal route, into the distal colon once a day for three consecutive days. On the day following the last administration, the animals were sacrificed and the distal colon was isolated, weighed, macroscopically examined, and processed for histology. Additional experiments in rat splenocytes, performed in order to elucidate the anti-inflammatory
\end{abstract}

G. Celasco $(\bowtie) \cdot$ L. Moro $\cdot$ R. Bozzella

Cosmo Research and Development Srl, Via C. Colombo 1, 20020 Lainate, MI, Italy

e-mail: giuseppe.celasco@ cosmopharmaceuticals.com

K. Mangano - C. Quattrocchi - C. Aiello · M. Donia · P. Fagone Dipartimento di Scienze Biomediche, Università di Catania, Catania, Italy

\section{R. Di Marco}

Dipartimento di Scienze per la Salute, Università del Molise, Campobasso, Italy

R. Di Marco

Istituto Neurologico del Mediterraneo, Neuromed, Pozzilli, IS, Italy mechanisms of CB-01-05, were performed. Results Among the tested items, only CB-01-05 at doses ranging from 0.2 to $0.9 \mathrm{mg}$ was significantly effective in reducing colon weight increase and in improving both the mucosal damaged area and the histological score. The other LMWHs resulted far less effective, showing decreasing activity closely related with the decrease of their molecular weight, thus demonstrating their biological nonequivalence. CB01-05 resulted also more active than UFH. CB-01-05 was shown to interfere with cytokines production by rat splenocytes, mainly inhibiting interferon (IFN)- $\gamma$ expression. Conclusions CB-01-05 instilled into the colon is well tolerated, has strong anti-inflammatory effect on DNBinduced colitis in rat, and is the most effective agent among other LMWHs and UFH. These results suggest that the anti-inflammatory activity of CB-01-05, together with its topical administration, could represent a new approach in the management of ulcerative colitis.

Keywords Parnaparin - Low-molecular-weight heparin . Colon delivery $\cdot$ Experimental colitis $\cdot$ Rat

\section{Introduction}

Inflammatory bowel disease (IBD) encompasses ulcerative colitis (UC) and Crohn's disease (CD), both of which are chronic, recurrent, nonspecific intestinal inflammatory processes of unknown aetiology. Current medical treatment of IBD, titrated according to the severity of the disease and to the individual response, includes 5-aminosalicylic acid (ASA) derivatives, corticosteroids, immunosuppressants, and most recently biologic agents mainly targeted against tumor necrosis factor (TNF)- $\alpha$. Among the emerging treatments for ulcerative colitis, the parenteral administration of 
low-molecular-weight heparins (LMWHs), i.e., dalteparin, enoxaparin, nadroparine, reviparin, deligoparin, and tinzaparin, was judged clinically useful by some authors [1-3], but questioned by others [4-8]. The administration of LMWHs by oral route has recently been attempted, resulting safe and effective in corticosteroid-resistant UC patients [9]. In spite of these encouraging results, this route of administration did not gain credit due to the conviction that LMWHs administered in conventional oral formulations are ineffective since they are inactivated in the upper gastrointestinal tract, thus not reaching therapeutic concentrations in the colon. The development of a novel oral extended-release technology $\left(\mathrm{MMX}^{\mathrm{TM}}\right.$, Cosmo Technologies Ltd., Dublin) able to deliver active substances directly on the mucosal surface of the colon, while avoiding all limitations closely related to the conventional oral formulations, offers a promising tool for IBD treatment. This concept has been recently supported by the observation that oral administration of enoxaparinloaded microspheres proved to be effective in experimentally induced colitis in mice [10]. The first question to be answered in developing a new oral, colon-release formulation containing LMWHs is to ascertain the real topical activity of the substances arriving in direct contact with the inflamed mucosa of the colon. A preliminary requirement to solve this issue is the availability of well-proven and reproducible animal models of colonic inflammation. The experimental colitis in rodents, induced by various chemical substances, i.e., dinitrobenzene sulfonic acid (DNB), trinitrobenzene sulfonic acid (TNB), dinitrofluorobenzene (DNFB), dextran sulfate sodium (DSS), oxazolone (OXA), iodoacetamide, or acetic acid, is considered a suitable model resembling the human IBD [10-17]. In this experimental model the parenteral administration of unfractionated heparin (UFH) and some LMWHs (i.e., enoxaparin, dalteparin) resulted effective [10-13, 16, 17]. Nevertheless, there is little information about their activity after intracolonic instillation [10]. In this paper we report the activity of CB01-05 (parnaparin sodium), a LMWH with a mean molecular weight of about 5,700, compared to a series of other LMWHs and to UFH, administered into the lumen of the colon in DNB-induced colitis in rat.

\section{Materials and Methods}

Animals

Adult male Wistar rats (Charles River Italy) of about 200 $250 \mathrm{~g}$ body weight were used in our experiments. Animals were kept in temperature- and light-controlled rooms, maintained at a constant temperature of approximately $24^{\circ} \mathrm{C}$ and $12 \mathrm{~h}$ of light/day. Animals were fed with standard animal pellets (Mucedola, Italy) and tap water ad libitum. The experiments were approved by the local Institutional Ethical Committee, and were performed in agreement with the Italian Legislative Decree 116/ 27.01.1992 concerning the protection of animals used for experimental purpose or other scientific scope.

\section{Products Used and Their Characteristics}

CB-01-05, the other LMWHs, and UFH, used in our experiments, are listed in Table 1, showing the internal product code, batch number, mean molecular weight, and specific activity.

\section{Induction of DNB-Colitis and Topical Treatment}

Groups of $8-10$ rats were used. Under light ether anaesthesia, each animal was intracolonically instilled with $30 \mathrm{mg}$ of DNB dissolved in $0.25 \mathrm{ml}$ of ethanol $50 \%$. The administration of the irritant was made by a catheter (outer diameter $0.3 \mathrm{~mm}$ ) placed about $7 \mathrm{~cm}$ proximal to the anus. After DNB instillation, $0.5 \mathrm{ml}$ of air was insufflated, after which the catheter was removed. CB-01-05 (0.005$0.9 \mathrm{mg})$, LMWH-A, B, C (0.3-0.6 mg), and UFH (0.6 mg) were dissolved in $0.25 \mathrm{ml}$ of saline containing sodium cholate $1 \%$ and were administered by intracolonic route, with the same procedure described for the administration of the irritant. The treatment was repeated for three consecutive days, $24 \mathrm{~h}$ apart, beginning on the day after colitis induction. Control groups of animals were instilled with the vehicle only. On the day following the last colonic instillation (day 5 of experiment), the animals were euthanized by ether inhalation.

\section{Macroscopic Evaluation of Colonic Damage}

Immediately after sacrifice, the rats were laparatomized and the intestine was exteriorized. The colon was isolated, carefully cleaned from mesenterium, vessels, and fat, and was placed unstretched on a ruler. A $10-\mathrm{cm}$ segment of the distal colon was cut and was weighed after gentle rinsing of the lumen with saline. Then, the isolated portion of the

Table 1 Products used and their characteristics

\begin{tabular}{llll}
\hline Product code & Batch no. & $\begin{array}{l}\text { Mean molecular } \\
\text { weight }\end{array}$ & $\begin{array}{l}\text { Specific activity } \\
\text { (IU/mg) }\end{array}$ \\
\hline CB-01-05 & 92308 & 5,760 & 104.9 anti-Xa \\
LMWH-A & G0101 & 5,304 & 96.1 anti-Xa \\
LMWH-B & 93284 & 3,110 & 66.9 anti-Xa \\
LMWH-C & S0108 & 2,601 & 43.1 anti-Xa \\
UFH & 93342 & - & 197.4 anticlotting \\
\hline
\end{tabular}

LMWH, low-molecular-weight heparin; UFH, unfractionated heparin 
colon was longitudinally opened by button-scissors and pinned down on a cork-table with the mucosal surface oriented to the observer. The area of the damaged mucosa (MDA) was measured by a caliper and was expressed in $\mathrm{mm}^{2}$ [13].

\section{Histological Evaluation of Colonic Damage}

The histological score (HS) was calculated on the damaged areas of the colonic samples which were fixed in phosphate buffered formalin, embedded in paraffin wax, 5 - $\mu$ m-thick sectioned, and stained with haematoxylin-eosin. An experienced blinded observer evaluated the specimens. Histological scoring was determined by examining each specimen for the following features of damage: depth and extent of necrosis, presence and extent of inflammation, and fibrosis. Each item was scored according to the severity $(0=$ no damage, to $4=$ extensive/severe damage $)$, and the scores for each item were added up for each specimen to obtain the total score, as described by Dotan et al. [13].

Determination of Cytokines Production by Rat Splenocytes

In order to investigate the possible role of CB-01-05 in inflammation, the effect of CB-01-05 and UFH on cytokines production by rat splenocytes was also assessed. Spleen mononuclear cells were collected from healthy untreated rats. The cells, plated $\left(2 \times 10^{6}\right)$ in triplicate in flat-bottomed microtiter plates (Costar, Cambridge, MA), were grown in complete culture medium (RPMI 1640, 10\% heat-inactivated foetal calf serum (Invitrogen, Milano, Italy), $2 \mathrm{nM} / \mathrm{ml}$ L-glutamine, $100 \mathrm{U} / \mathrm{ml}$ penicillin, and $100 \mu \mathrm{g} / \mathrm{ml}$ streptomycin). The cells were incubated for $72 \mathrm{~h}$, at $37^{\circ} \mathrm{C}$ with $5 \% \mathrm{CO}_{2}$, in the presence or in absence of $4 \mu \mathrm{g} / \mathrm{ml}$ Con-A or $2 \mu \mathrm{g} / \mathrm{ml}$ phytohemagglutinin (PHA) $+0.3 \mu \mathrm{g} / \mathrm{ml}$ lipopolysaccharide (LPS) (Sigma Chemical Co., St. Louis, MO), and with various concentrations of CB-01-05 or UFH (4, 20 and $100 \mathrm{IU} / \mathrm{ml}$ each). Dexamethasone $(25 \mathrm{mM} / \mathrm{ml})$ was used as positive control. After incubation, the supernatants were collected and stored at $-80^{\circ} \mathrm{C}$ until cytokines determination. Concentration of IFN- $\gamma$, TNF- $\alpha$, interleukin (IL)-2, and IL-10 (pg/ $\mathrm{ml}$ ) in the supernatants was determined by solid-phase enzyme-linked immunosorbent assay (ELISA) using commercial kits (Biosource Europe, Nivelles, Belgium), according to manufacturer's instructions. To allow statistical evaluation of the data, the samples in which the value of the cytokine was detected below the limit of sensitivity of the method were conventionally assigned values equivalent to this limit (i.e., IFN- $\gamma=21 \mathrm{pg} / \mathrm{ml}$; TNF- $\alpha$, IL2 , and $\mathrm{IL}-10=15 \mathrm{pg} / \mathrm{ml}$ ).
Statistical Analysis

Statistical analysis for significant differences between the treated groups and the relevant vehicle control groups was performed according to the Student's test for unpaired data, or applying the nonparametric Mann-Whitney test. A value of $P<0.05$ was considered to be statistically significant.

\section{Results}

\section{Experimental Colitis}

The results obtained in three independent essays are expressed as mean values \pm standard deviation (SD) (Table 2), and as percentage reduction/improvement versus the relevant vehicle control groups (Table 3). The colitis induction influenced negatively the body growth of the animals in both the control and the treated groups. In the vehicle control groups, the intraluminal instillation of DNB increased the weight of the distal colon more than two times, as compared with intact animals (historical data collected in groups of intact animals ranged from $0.76 \pm 0.11$ to $0.82 \pm 0.16 \mathrm{~g} / 10 \mathrm{~cm}$ length), and induced striking macroscopic and histological mucosal damages in this portion of the colon. All these intestinal DNB-induced effects were variably influenced by the intracolonic administration of CB-01-05 and the other reference substances, so that the profiles of activity of the tested items greatly differed from each other (Table 2). In particular, as shown in Table 3 reporting the percentage variations of activity, CB-01-05 (mean mol. wt. 5,760) was the most active compound of the series, showing a significant $(P<0.01)$, dose-related percentage reduction of both colon overweight and mucosal damaged area (MDA), and also a significant percentage improvement of the histological score (HS). The effect began from the dose of 0.2 $\mathrm{mg}$, and became fully expressed at the doses of 0.6 and $0.9 \mathrm{mg}$, which displayed very similar activity. Compared to CB-01-05, UFH $(0.6 \mathrm{mg})$ resulted about three times less active on the colon weight, and slightly less effective on MDA reduction (36\% vs. $43 \%$ ). The other LMWHs (LMWH-A [mean mol. wt. 5,304], LMWH-B [mean mol. wt. 3,110], and LMWH-C [mean mol. wt. 2,601]) were quite ineffective at the tested doses of $0.3-0.6 \mathrm{mg}$. All treatments were well tolerated and no obvious effects on survival rate or macroscopic mucosal haemorrhages were observed in the animals.

\section{Effect on Cytokines Production by Rat Splenocytes}

The results for INF- $\gamma$, TNF- $\alpha$, IL-2, and IL-10 production after $72 \mathrm{~h}$ of incubation are reported in Table 4. The 
Table 2 Effect of CB-01-05, other LMWHs, and UFH in DNB-induced experimental colitis in rat (mean values \pm SD)

\begin{tabular}{|c|c|c|c|c|c|c|c|}
\hline \multirow{2}{*}{$\begin{array}{l}\text { Assay } \\
\text { no. }\end{array}$} & \multirow{2}{*}{$\begin{array}{l}\text { Intracolonic } \\
\text { treatment }\end{array}$} & \multirow{2}{*}{$\begin{array}{l}\text { Daily } \\
\text { dose } \\
(\mathrm{mg})\end{array}$} & \multicolumn{2}{|c|}{ Av. body weight (g) } & \multirow{2}{*}{$\begin{array}{l}\text { Distal colon weight } \\
(\mathrm{g} / 10 \mathrm{~cm})\end{array}$} & \multirow{2}{*}{$\begin{array}{l}\text { Mucosal damaged } \\
\text { area (MDA) }\left(\mathrm{mm}^{2}\right)\end{array}$} & \multirow{2}{*}{$\begin{array}{l}\text { Histological } \\
\text { score } \\
\text { (HS) }\end{array}$} \\
\hline & & & Initial & Final & & & \\
\hline \multirow[t]{6}{*}{ I } & Control & - & $239 \pm 15.1$ & $223 \pm 17.2$ & $1.93 \pm 0.3$ & $689.1 \pm 138.2$ & $9.1 \pm 2.5$ \\
\hline & CB-01-05 & 0.005 & $239 \pm 13.0$ & $223 \pm 16.1$ & $2.19 \pm 0.6$ & $712.1 \pm 233.9$ & $9.1 \pm 3.0$ \\
\hline & & 0.016 & $246 \pm 3.3$ & $228 \pm 8.9$ & $1.99 \pm 0.2$ & $721.3 \pm 67.7$ & $9.0 \pm 1.2$ \\
\hline & & 0.06 & $246 \pm 4.2$ & $225 \pm 15.7$ & $2.10 \pm 0.5$ & $653.1 \pm 202.0$ & $6.9 \pm 1.8$ \\
\hline & & 0.2 & $245 \pm 5.3$ & $239 \pm 8.8$ & $1.59 \pm 0.4$ & $516.0 \pm 184.9$ & $5.3 \pm 2.4^{*}$ \\
\hline & & 0.6 & $236 \pm 17.1$ & $224 \pm 16.9$ & $1.50 \pm 0.3^{*}$ & $393.6 \pm 166.9^{*}$ & $4.0 \pm 1.7^{*}$ \\
\hline \multirow[t]{6}{*}{ II } & Control & - & $240 \pm 11.2$ & $225 \pm 9.9$ & $1.88 \pm 0.4$ & $711.9 \pm 137.5$ & $8.4 \pm 2.3$ \\
\hline & CB-01-05 & 0.3 & $244 \pm 4.9$ & $226 \pm 8.3$ & $1.52 \pm 0.5$ & $557.3 \pm 142.6^{*}$ & $5.5 \pm 3.2^{*}$ \\
\hline & LMWH-A & 0.6 & $242 \pm 11.2$ & $231 \pm 12.2$ & $1.25 \pm 0.2 *$ & $382.2 \pm 162.1^{*}$ & $4.2 \pm 1.41^{*}$ \\
\hline & LMWH-C & 0.9 & $243 \pm 10.6$ & $233 \pm 14.7$ & $1.22 \pm 0.4^{*}$ & $369.8 \pm 185.3^{*}$ & $3.5 \pm 2.1^{*}$ \\
\hline & & 0.6 & $238 \pm 8.8$ & $225 \pm 13.5$ & $1.74 \pm 0.5$ & $586.0 \pm 183.4$ & $6.0 \pm 2.7$ \\
\hline & & 0.6 & $239 \pm 9.8$ & $224 \pm 6.4$ & $1.85 \pm 0.2$ & $524.4 \pm 292.5$ & $8.3 \pm 1.9$ \\
\hline \multirow[t]{4}{*}{ III } & Control & - & $242 \pm 7.1$ & $218 \pm 9.9$ & $1.90 \pm 0.20$ & $486.5 \pm 106.2$ & n.a. \\
\hline & LMWH-B & 0.3 & $244 \pm 9.7$ & $223 \pm 10.2$ & $1.80 \pm 0.30$ & $391.8 \pm 238.7$ & n.a. \\
\hline & UFH & 0.6 & $250 \pm 6.4$ & $224 \pm 8.8$ & $1.80 \pm 0.20$ & $420.2 \pm 212.3$ & n.a. \\
\hline & & 0.6 & $253 \pm 10.1$ & $238 \pm 11.6$ & $1.70 \pm 0.30$ & $312.5 \pm 209.4$ & n.a. \\
\hline
\end{tabular}

$* P<0.01$ versus the relevant control group. n.a. $=$ not assessed; LMWH $=$ low-molecular-weight heparin; UFH $=$ unfractionated heparin

Table 3 Effect of CB-01-05, other LMWHs, and UFH in DNBinduced colitis in rat (percentage of activity versus relevant control groups)

\begin{tabular}{lllll}
\hline $\begin{array}{l}\text { Intracolonic } \\
\text { treatment }\end{array}$ & $\begin{array}{l}\text { Daily } \\
\text { dose } \\
(\mathrm{mg})\end{array}$ & $\begin{array}{l}\text { Distal } \\
\text { colon } \\
\text { weight } \\
\text { reduction } \\
(\%)\end{array}$ & $\begin{array}{l}\text { MDA } \\
\text { reduction } \\
(\%)\end{array}$ & $\begin{array}{l}\text { HS } \\
\text { improvement } \\
(\%)\end{array}$ \\
\hline CB-01-05 & 0.005 & 0 & 0 & 0 \\
& 0.016 & 0 & 0 & 1 \\
& 0.06 & 0 & 5 & 24 \\
& 0.2 & 18 & 25 & $42^{*}$ \\
& 0.3 & 19 & $22^{*}$ & $34^{*}$ \\
LMWH-A & 0.6 & $22^{*}$ & $43^{*}$ & $56^{*}$ \\
LMWH-B & 0.9 & $35^{*}$ & $48^{*}$ & $58^{*}$ \\
& 0.6 & 7 & 18 & 28 \\
LMWH-C & 0.3 & 5 & 19 & n.a. \\
UFH & 0.6 & 5 & 14 & n.a. \\
\hline
\end{tabular}

$* P<0.01$ versus the relevant control group. n.a. $=$ not assessed; LMWH = low-molecular-weight heparin; $\quad$ UFH $=$ unfractionated heparin

stimulation of splenocytes with Con-A or with PHA + LPS induced a consistent expression of all cytokines which was nearly completely suppressed by incubation with dexamethasone $25 \mathrm{mM} / \mathrm{ml}$. CB-01-05 and UFH significantly inhibited $(P<0.05)$ IFN $-\gamma$ production even at the lowest tested concentration. The expression of TNF- $\alpha$ and IL-10 was only moderately increased by the incubation with both glycosaminoglycans, whereas IL-2 production was greatly increased by UFH more than four times the value of the control stimulated group.

\section{Discussion}

This study has demonstrated that DNB-induced experimental colitis in rat is a useful and reliable tool to evaluate the topical anti-inflammatory activity of heparin derivatives, when delivered in direct contact with the mucosa of the colon. Furthermore it was demonstrated for the first time that CB-01-05, a LMWH with a mean molecular weight of about 5,760, when repeatedly applied to the colonic mucosa, significantly ameliorates the macroscopic and histological scores of DNB-induced colitis in rat. Our data are supported by the results previously reported by Pellequer et al. [10] concerning the efficacy of the rectal administration of enoxaparin in TNB- and OXA-induced colitis in mice. Nevertheless, due to the large differences in the design of the various animal models, a direct comparison of activity between the two LMWHs is not appropriate. The best anti-inflammatory effect of CB-01-05 was achieved with topical doses ranging from 0.6 to $0.9 \mathrm{mg}$. Considering that both of these doses displayed very similar effects, the dose of $0.6 \mathrm{mg}$ could be set as the best effective dose. This dose is not too far from the dose of 
Table 4 Cytokine release (pg/ml) from rat splenocytes after $72 \mathrm{~h}$ of incubation (mean values \pm SD)

\begin{tabular}{|c|c|c|c|c|c|}
\hline Treatment & Concentration & $\begin{array}{l}\text { IFN- } \gamma \\
(\text { Con-A) }\end{array}$ & $\begin{array}{l}\text { TNF- } \alpha \\
(\mathrm{PHA}+\text { LPS })\end{array}$ & $\begin{array}{l}\text { IL-2 } \\
\text { (Con-A) }\end{array}$ & $\begin{array}{l}\text { IL-10 } \\
\text { (PHA + LPS) }\end{array}$ \\
\hline None & - & $21 \pm 0$ & $15 \pm 0$ & $15 \pm 0$ & $30.5 \pm 27$ \\
\hline Stimulated control & - & $7076 \pm 2804$ & $61 \pm 11$ & $3342 \pm 788$ & $183 \pm 13$ \\
\hline Dexamethasone & $25 \mathrm{mM} / \mathrm{ml}$ & $21 \pm 0^{*}$ & $15 \pm 0^{*}$ & $15 \pm 0 *$ & $76 \pm 12 *$ \\
\hline \multirow[t]{3}{*}{ UFH } & $4 \mathrm{IU} / \mathrm{ml}$ & $3763 \pm 2862 *$ & $85 \pm 19$ & $4416 \pm 568^{*}$ & $193 \pm 54$ \\
\hline & $20 \mathrm{IU} / \mathrm{ml}$ & $3395 \pm 2251 *$ & $85 \pm 18^{*}$ & $9165 \pm 1847^{*}$ & $209 \pm 88$ \\
\hline & $100 \mathrm{IU} / \mathrm{ml}$ & $1139 \pm 388^{*}$ & $104 \pm 35^{*}$ & $14731 \pm 3804^{*}$ & $242 \pm 55^{*}$ \\
\hline \multirow[t]{3}{*}{ CB-01-05 } & $4 \mathrm{IU} / \mathrm{ml}$ & $3079 \pm 1475^{*}$ & $76 \pm 14$ & $5512 \pm 1442 *$ & $168 \pm 24$ \\
\hline & $20 \mathrm{IU} / \mathrm{ml}$ & $3394 \pm 1573 *$ & $72 \pm 17$ & $6404 \pm 1002 *$ & $229 \pm 66$ \\
\hline & $100 \mathrm{IU} / \mathrm{ml}$ & $986 \pm 1447^{*}$ & $81 \pm 19 *$ & $6414 \pm 4808$ & $258 \pm 105$ \\
\hline
\end{tabular}

$* P<0.05$ versus the relevant stimulated control group. UFH $=$ unfractionated heparin

topical budesonide $(0.15 \mathrm{mg})$ which was tested by Palment et al. [15] in TNB-induced colitis in rat and was found to be effective. CB-01-05 was also more effective than UFH, whereas the other evaluated LMWHs (A, B, and C) did not show noticeable activity at the tested doses. These data demonstrate that UFH and the various LMWHs assessed are not biologically equivalent. The evident difference of anti-inflammatory activity observed among these glycosaminoglycans could be in relationship with their different molecular weight. In fact, it is possible that in the process of production of LMWHs, obtained by partial hydrolysis or enzymatic degradation of parent heparin, some of the biological properties pertaining to UFH [18-21] could be modified or partially lost. This hypothesis is supported by the observation that LMWH-A, LMWH-B, and LMWH-C showed a decreasing activity according to the decrease of their molecular weight. As a consequence, we believe that an ideal LMWH proposed for topical use in UC should have a mean molecular weight not too far from 5,700, as in the case of CB-01-05. This assumption is further supported by the recent observation that CB-01-05, orally administered to humans as coated colon-release tablets assembled by the $\mathrm{MMX}^{\mathrm{TM}}$ technology, was found to be effective and safe in a pilot study in patients affected by UC [22]. In the present animal model we did not examine in depth the mechanism of action underlying the better efficacy of CB01-05. Nevertheless, the quick response elicited by CB-0105 is predictive for its effect mainly in the acute phase of the inflammatory process. Our observations made in splenocytes of untreated rats show that CB-01-05 interferes with cytokines profile, reducing the production of IFN- $\gamma$ and increasing the expression of TNF- $\alpha$, IL-2, and IL-10. The combined reduction of IFN- $\gamma$ and the increase of IL-10 could account for the observed anti-inflammatory activity of CB-01-05, considering the pivotal role of IFN- $\gamma$ in impairing intestinal healing [23], and the well-known immunoregulatory function of IL-10 [24]. CB-01-05 also shows a profile of activity different from that of UFH, resulting more effective as an inhibitor of IFN- $\gamma$ production, but consistently less potent in eliciting the release of TNF- $\alpha$ and, in particular, IL-2. Although the effects of CB01-05 on cytokines production are in agreement with the known ability of dalteparin and other heparin derivatives to influence cytokines production and to arrest immune inflammation in rodents $[16,17,25]$, we cannot exclude the involvement of additional mechanisms. Among these putative mechanisms increase of expression of some growth factors [26], decrease of nitric oxide synthesis [18, $20,27]$, as well as effects on intestinal microcirculation [12, 28], and leucocyte-endothelial interactions [19] could be involved in the activity of CB-01-05. On the other hand, the observation that macroscopic mucosal haemorrhages were not severer in CB-01-05 group than in the control groups suggests that the local activity of CB-01-05 is not mediated by a direct anticoagulant mechanism. These findings are particularly interesting in term of safety, suggesting that colonic delivery of CB-01-05 should not increase the risk of intestinal bleeding, as has been observed with subcutaneous administration of dalteparin in TNB-induced rat colitis [16].

In conclusion, our data show that CB-01-05 is well tolerated and, on the contrary to other tested LMWHs, exerts a potent local anti-inflammatory effect in experimental DNB-induced colitis. Although the precise mechanism of the anti-inflammatory activity of CB-01-05 is not elucidated in depth, the present data, supported by the observation that enoxaparin-loaded microspheres is effective by oral route [10], and by the preliminary encouraging clinical results obtained with CB-01-05 $\mathrm{MMX}^{\mathrm{TM}}$ in human UC [22], suggest that CB-01-05, orally administered in an appropriate colon-release formulation, is worthy to be assessed in randomized, controlled clinical trials.

Acknowledgment This work has been sponsored by Cosmo Research and Development Srl, Lainate (MI), Italy. 
Open Access This article is distributed under the terms of the Creative Commons Attribution Noncommercial License which permits any noncommercial use, distribution, and reproduction in any medium, provided the original author(s) and source are credited.

\section{References}

1. Torkvist L, Thorlacius H, Sjoquist U, Bohman L, Lapidus A, Flood L, Agren B, Radus J, Lofberg R (1999) Low molecular weight heparin as adjuvant therapy in active ulcerative colitis. Aliment Pharmacol Ther 13:1323-1328. doi:10.1046/j.13652036.1999.00599.x

2. Dotan I, Hallak A, Arber N, Santo M, Alexandrowitz A, Knaani Y, Hershkoviz R, Brazowski E, Halpern Z (2001) Low-dose lowmolecular weight heparin (enoxaparin) is effective as adjuvant treatment in active ulcerative colitis: an open trial. Dig Dis Sci 46:2239-2244. doi:10.1023/A:1011979418914

3. Vrij AA, Jansem JM, Schoon EJ, de Bruine A, Hemker HC, Stockbrugger RW (2001) Low molecular weight heparin treatment in steroid refractory ulcerative colitis: clinical outcome and influence on mucosal capillary thrombi. Scand J Gastroenterol 234(Suppl):41-47. doi:10.1080/003655201753265091

4. De Bièvre MA, Vrij AA, Schoon EJ, Dijkstra G, de Jong AE, Oberndorff-Klein Woolthuis AH, Hemker HC, Stockbrugger RW (2007) Randomized, placebo-controlled trial of low molecular weight heparin in active ulcerative colitis. Inflamm Bowel Dis 13:753-758. doi:10.1002/ibd.20085

5. Zezos P, Papaioannou G, Nikolaidis N, Patsiaoura K, Papageorgiou A, Vassiliadis T, Giouleme O, Evgenidis N (2006) Lowmolecular-weight heparin (enoxaparin) as adjuvant therapy in the treatment of active ulcerative colitis: a randomized, controlled, comparative study. Aliment Pharmacol Ther 23:1443-1453. doi:10.1111/j.1365-2036.2006.02870.x

6. Korzenik J, Miner P jr, Stanton D, Isaakcs K, Zimmerman E, De Viliers W, Venuti R (2003) Multicenter, randomized, placebocontrolled trial of deligoparin (ultra low molecular weight heparin) for active ulcerative colitis. Gastroenterology AGA Abstr. 539

7. Bloom S, Kiilwerich S, Lassen MR, Forbess A, Leioer K, Langholz E, Irvine EJ, O'Morain C, Lowson D, Orm S (2004) Low molecular weight heparin (tinzaparin) vs. placebo in the treatment of mild to moderately active ulcerative colitis. Aliment Pharmacol Ther 19:871-878. doi:10.1111/j.1365-2036.2004.01926.x

8. Shen J, Ran ZH, Tong JL, Xiao SD (2007) Meta-analysis: the utility and safety of heparin in the treatment of active ulcerative colitis. Aliment Pharmacol Ther 26:653-663

9. Cui HF, Jiang XL (1999) Treatment of corticosteroid-resistant ulcerative colitis with oral low molecular weight heparin. World $\mathbf{J}$ Gastroenterol 5:448-450

10. Pellequer Y, Meissner Y, Ubrich N, Lamprecht A (2007) Epithelial heparin delivery via microspheres mitigates experimental colitis in mice. JPET 321:726-733. doi:10.1124/jpet.106.117226

11. Korzenik J, Hsu A, Robert ME (1998) Effect of heparin on dextran sulphate sodium-induced colitis. Dig Dis Sci 43:1800 1805. doi:10.1023/A:1018800207063

12. Fries W, Pagiaro E, Canova E, Carraio P, Gasparini G, Pomeri F, Martin A, Parlotto C, Mazzon E, Sturniolo GC, Longo G (1998) The effect of heparin on trinitrobenzene sulphonic acid-induced colitis in the rat. Aliment Pharmacol Ther 12:229-236. doi:10.1046/j.1365-2036.1998.00293.x

13. Dotan I, Hershkoviz R, Karmeli F, Brazowski E, Peled Y, Rachmilewitz D, Halpern Z (2001) Heparin and low-molecularweight heparin (enoxaparin) significantly ameliorate experimental colitis in rats. Aliment Pharmacol Ther 15:1687-1697. doi:10.1046/j.1365-2036.2001.01079.x
14. Dieleman LA, Palmen MJHJ, Akol H, Bloemena E, Pena AS, Meuwissen SGM, Van Rees EP (1998) Chronic experimental colitis induced by dextran sulphate sodium (DSS) is characterized by Th1 and Th2 cytokines. Clin Exp Immunol 114:385-391. doi:10.1046/j.1365-2249.1998.00728.x

15. Palmen MJHJ, Dieleman LA, Soesatyo M, Pena AS, Meuwissen SGM, Van Rees EP (1998) Effect of local budesonide treatment on the cell-mediated immune response in acute and relapsing colitis in rats. Dig Dis Sci 43:2518-2525. doi:10.1023/ A: 1026606904531

16. Xia B, Han H, Zhang K-J, Li J, Guo G-S, Gong L-L, Zeng X-C, Liu J-Y (2004) Effects of low molecular weight heparin on platelet surface P-selectin expression and serum interleukin-8 production in rats with trinitrobenzene sulphonic acid-induced colitis. World J Gastroenterol 10:729-732

17. Wan MX, Liu Q, Wang Y, Thorlacius H (2002) Protective effect of low molecular weight heparin on experimental colitis: role of neutrophil recruitment and TNF-alpha production. Inflamm Res 51:182-187. doi:10.1007/PL00000290

18. Papa A, Danese S, Gasbarrini A, Gasbarrini G (2000) Review article: potential therapeutic applications and mechanisms of action of heparin in inflammatory bowel disease. Aliment Pharmacol Ther 14:1403-1409. doi:10.1046/j.1365-2036.2000.00860.x

19. Salas A, Sans M, Soriano A, Reverter JC, Anderson D, Piqué JM, Panés J (2000) Heparin attenuates TNF- $\alpha$ induced inflammatory response through a CD11b dependent mechanism. Gut 47:88-96. doi:10.1136/gut.47.1.88

20. Michell NP, Lalor P, Langman MJS (2001) Heparin therapy for ulcerative colitis? Effects and mechanisms. Eur J Gastroenterol Hepatol 13:449-456. doi:10.1097/00042737-200104000-00026

21. Elsayed E, Becker C (2003) The impact of heparin compounds on cellular inflammatory responses: a construct for future investigation and pharmaceutical development. J Thromb Thrombolysis 15:11-18. doi:10.1023/A:1026184100030

22. Saibeni S, Spina L, Signorelli C, Pastorelli L, De Franchis R, Moro L, Villa R, Bozzella R, Celasco G, Vecchi M (2006) Safety and efficacy of oral, colonic-release, Low Molecular Weight Heparin-MMX ${ }^{\mathrm{TM}}$ for the treatment of mild to moderate left-sided ulcerative colitis: Preliminary report of a pilot study. Gastroenterology 130(Suppl 2):AGA Abstr. W 1227

23. Leaphart CL, Qureshi F, Cetin S, Li J, Dubowski T, Batey C, Beer-Stolz D, Guo F, Murray SA, Hackam DJ (2007) Interferon- $\gamma$ inhibits intestinal restitution by preventing gap junction communication between enterocytes. Gastroenterology 132:23952411. doi:10.1053/j.gastro.2007.03.029

24. Asadullah K, Sterry W, Volk HD (2003) Interleukin-10 therapyreview of a new approach. Pharmacol Rev 55:241-269. doi:10.1124/pr.55.2.4

25. Cahalon L, Lider O, Schor EJ, Avron A, Gilat D, Hershkoviz R, Margalit R, Eshel A, Shoseyev O, Cohen R (1997) Heparin disaccharides inhibit tumor necrosis factor-alpha production by macrophages and arrest immune inflammation in rodents. Int Immunol 9:1517-1522. doi:10.1093/intimm/9.10.1517

26. Levine A, Kenet G, Bruck R, Avni Y, Avinoach I, Aeed H, Matas Z, David M, Yayon A (2002) Effect of heparin on tissue binding activity of fibroblast growth factor and heparin-binding epidermal growth factor in experimental colitis in rats. Pediatr Res 51:635640. doi:10.1203/00006450-200205000-00015

27. Otsuka M, Tsuchiya S, Aramaki Y (2006) Comparison of inhibitory effects of polyanions on nitric oxide production by macrophages stimulated with LPS. Biol Pharm Bull 29:499-502. doi:10.1248/bpb.29.499

28. Hatoum OA, Heidemann J, Binion DG (2006) The intestinal microvasculature as a therapeutic target in inflammatory bowel diseases. Ann NY Acad Sci 1072:78-97. doi:10.1196/ annals.1326.003 